\title{
The RIM Initiative in Vietnam: 'Prioritise Rapid Results rather than Publishable Results'
}

\author{
Henry Lucas and Jay Chaudhuri
}

\begin{abstract}
The 2009 Rapid Impact Monitoring (RIM) initiative in Vietnam was one of a number of studies undertaken in East Asia and Pacific countries to assess the initial poverty and social impacts of the global economic crisis. In Vietnam, the exercise was undertaken by the Centre for Analysis and Forecasting (CAF) of the Vietnamese Academy of Social Sciences (VASS). A favourable response to the findings led to additional RIM exercises in 2010 and 2011. It has been suggested that it should become a permanent feature of the policy process in Vietnam, assessing the impacts of both external shocks and major policy initiatives. This case study was intended to assess the RIM as an RTM tool, and more generally to assess the potential value of qualitative RTM exercises. The key finding was that such exercises can play an important role in situations where current, reliable data from other sources is lacking.
\end{abstract}

\section{Introduction}

The 2009 Rapid Impact Monitoring (RIM) initiative in Vietnam was one of a number of studies undertaken in East Asia and Pacific countries in an attempt to assess the initial poverty and social impacts of the global economic crisis (Turk and Mason 2010; UNICEF 2010). The study designs were based on an initial identification of key mechanisms by which the impacts of the crisis might be transmitted. In Vietnam, the Centre for Analysis and Forecasting (CAF), working in collaboration with international partners, ${ }^{1}$ developed a working hypothesis that the most important mechanisms were labour market shocks resulting from falling demand for exports, falling domestic demand for goods and services, and slowing remittance flows. The objective of the study was to explore this hypothesis, determining how these mechanisms operated and the extent to which specific vulnerable groups might be affected.

A diverse range of study sites were selected to explore the potential effects of the crisis - on urban and rural enterprises, formal and informal labour markets, households dependent on remittance income, and minority and remote populations. A series of qualitative exercises were undertaken in these locations, mainly using a mixture of document analysis, one-to-one interviews, and focus group discussions (FGDs) that incorporated rapid appraisal methods with key informants, including ranking exercises and time lines. These were conducted with:

- Formal sector workers in export-oriented industries;

- Household enterprises dependent on export markets;

- Migrant workers in the informal sector in urban areas;

- Remittance-receiving households in rural areas; and

- Entrepreneurs, industrial zone managers, and commune and village leaders.

In each case, care was taken to reflect the views and experiences of both men and women, who make up a substantial proportion of the overall workforce in some sectors. Extended key informant interviews were also undertaken with community leaders, managers of firms and owners of local businesses to gain a general understanding as to how the shock was affecting 
a particular community, what coping strategies were being adopted and how events might unfold, to obtain additional information (e.g. administrative data) and to validate information obtained from target population groups. Sampling was purposive and based on findings from several smaller rounds of rapid assessments carried out in early 2009. Initially, the focus was on industrial parks, craft villages and urban mobile labour markets directly exposed to the impacts of the crisis. Observations in these areas led to a concern with the implications of high levels of rural-urban migration and selection of rural areas from which many migrants originated. Finally, there was a desire to test findings in other economic sectors and with other population groups, for example those living in remote mountainous regions. The sampling would appear to have been influenced by the desire to work within a reasonably constrained budget, which limited both the overall number of sites and the sample size (e.g. number of focus groups) at each site. The studies also had to be reasonably time-bound, given the need to produce timely information that could be used to design government responses to the crisis.

Assessment of sampling procedures, especially in terms of their implementation in the field, is constrained by the lack of detailed description of the fieldwork in later rounds. (The 'inevitable' delay between undertaking fieldwork and reflecting on it is one aspect of rapid monitoring that needs further exploration).The observations below therefore relate only to the initial round. Here, possibly because the aims of the study were not widely appreciated, the sample appears to have been partly determined by the accessibility of some respondents. For example, it would seem that some enterprises were reluctant to collaborate with researchers, possibly due to sensitivities relating to the downturn in their fortunes or laying off of workers. The difficulties encountered are described in an article based on research undertaken in two industrial parks close to Hanoi (Anh and Nguyen 2010). It was intended to conduct interviews in enterprises in just one of these sites, Thang Long. However, 'only two enterprises out of nearly 50 contacted agreed to meet with the researchers' and a nearby site, Quang Minh, was added, where 'personal contacts and connections' allowed data to be collected from two additional enterprises, where a total of 23 employees were interviewed. It was indicated that enterprises have become much more willing to engage in the more recent RIM exercises.

A study on craft villages was based on interviews and FGDs with ' 12 representatives from craft companies and cooperatives, 17 from household producers, 12 workers, with four being female, and six senior officials of the communes, villages and craft guilds' (Giang 2009). Another, on day labourers in Hanoi, drew on three FGDs with 16 workers and in-depth interviews with nine labourers in five labour markets (Phuong 2010). One of those involved in the initial design indicated that the 'small size and the sampling process mean that findings are illustrative rather than statistically representative or generalizable.'

The fieldwork was undertaken by CAF in collaboration with a range of other agencies including Oxfam GB, ActionAid, the Institute of Policy and Strategy for Agriculture and Rural Development (IPSARD), the Institute for Labour Science and Social Affairs (ILSSA) and the Vietnam Chamber of Commerce and Industry (VCCI). The fieldwork was undertaken over a relatively short period of time and resulting findings were made available as quickly as possible to feed into national discussions of the rapidly evolving economic crisis. The intention was to 'prioritize rapid results rather than publishable results' (Turk and Mason 2010: 55). While a number of reports have since been published, often relating to individual study sites, the circulation of briefing materials immediately following the study was limited to a relatively small number of stakeholders, initially national policymakers and then international partners. In line with the priority given to the national policy process, many of the initial outputs were in Vietnamese. They were used to inform the Vietnamese Academy of Social Sciences (VASS) monthly, quarterly and annual reports to the government, as well as CAF reports to two committees of the National Assembly (Economic Affairs and Social Affairs).

The initial study took place from March-May 2009, with a second round during August-September of the same year. A similar exercise, which excluded the tourism and ethnic minority sites, took place over AugustSeptember 2010 (round three), and another full 
round was carried out in August-September 2011 (round four). This timetable was strongly influenced by the need to provide timely information to meetings of the National Assembly. CAF is regarded as a key advisory agency by National Assembly members from the aforementioned committees.

The latest exercises from 2011 were undertaken in the sentinel sites used for the first three rounds, with a small number of additions. Specifically, round four intended to:

- Track changes since 2010 in the health of firms and the wellbeing of vulnerable groups (migrant workers, urban workers in informal sector, selected groups of agricultural workers and rural households);

- Monitor how a package of government policies aimed at combating the prevailing domestic macroeconomic instability known as Resolution 11, particularly those being intended to support agriculture, export, service industries and small and medium enterprises (SMEs), were being implemented;

- Monitor the extent to which a range of formal and informal social protection systems were assisting vulnerable groups; and

- Assess the poverty and distributional impacts of rising global and domestic food prices.

The overall need for the RIM study was based on perceived limitations of existing information sources in terms of timely policymaking. ${ }^{2}$ The primary responsibility for collecting and disseminating official data lies with the General Statistical Office (GSO), though central and line ministries also collect data for their own purposes. Key macroeconomic statistics on international trade flows, investment and prices are published in GSO monthly bulletins. Estimates of GDP and its components are available on a quarterly basis, and there is annual reporting of the national accounts. National accounts data are collected in enterprise surveys, which are conducted each year, with additional estimates derived from the household surveys undertaken every two years. It is intended that aggregate findings from a national labour force survey are available on a quarterly basis.

Those proposing the RIM study argued that, while these sources would continue to provide the core data required for policymaking, there were significant gaps in terms of the availability of timely, disaggregated data on the perceived impacts on, and responses of, enterprises, the labour force and households required for rigorous analysis that could feed into ongoing policy debates. They also identified a lack of reliable qualitative information that could provide an in-depth understanding of the processes underlying the transmission of the impact of economic shocks to enterprises, households and individuals, and the mechanisms by which they were able to cope with those impacts given the prevailing socioeconomic and policy environment.

\section{Quality of information}

Perhaps the central issue relating to the quality of RIM is that there remain diverse opinions as to what it is, what it should be and what precise role it can play. The original conception seems to have been a 'quick and not too dirty' qualitative study to provide information on the impact of the economic crisis when other sources of information were very limited. Interest in the findings then seems to have fed the demand to include more topics, add more questions on each topic and provide more quantitative data that would allow a more precise interpretation of the findings. This demand, often accompanied by financial incentives, increased the burden on both the researchers, particularly those in CAF, and those asked to participate as respondents. It would appear that this had adverse consequences. As indicated above, the study seems to have moved away from the use of traditional qualitative interviews and innovative rapid appraisal methods to a more questionnaire-based approach (though with mainly open-ended questions). This seems to have been a natural consequence of simply trying to ask too many questions over too short a time period, and there must be concerns that this will have affected the overall quality of the fieldwork.

It may also be worth considering the balance between expertise/experience in economics and other disciplines (sociology/anthropology/ participatory research) in the RIM team. The initial studies were very much focused on the impact of the crisis on employment, and considerable attention was paid to collecting data on the enterprises that could provide such information. Given this emphasis, it would have been natural for the economists to take a lead in study design. If RIM moves, as is currently 
suggested, to increase its focus on households and vulnerable populations, a serious review of the underlying methodological paradigm may be required.

As indicated above, the process for selecting sentinel sites, enterprises, individuals and households needs to be more carefully considered. As with some other qualitative studies, there is a tendency to argue that because it is 'purposive' sampling and not intended to be 'representative', there is little point in discussion of the sample design. On the contrary, precisely because RIM has not used probability sampling, there is a substantial need for detailed justification of the sampling process and assessment of its implications for the interpretation of findings. Clearly the sample is intended to be seen as representative in the sense that policymakers are invited to take decisions that will affect, for example, workers in traditional craft villages, on the basis of interviews with the RIM sample of such workers. It is therefore reasonable to explore questions as to the extent to which this sample may have been biased, for example in terms of selecting villages that were readily accessible or workers that were keen to cooperate. To what extent might responses have differed in other villages or if other workers had been interviewed? It may also be worth considering whether alternative forms of non-probability sampling (transect walking, quota sampling, etc.) that introduced a nonpurposive element into the process of selection at the site level of enterprises or employers within enterprises might increase the confidence of stakeholders in the eventual findings.

The technical quality of any rapid monitoring system is clearly important in terms of delivering timely and reliable information. However, technical quality is of limited consequence unless such systems have the potential to promote effective interventions or at least to influence policy. In this respect the RIM studies have achieved an enviable status. There is obviously considerable regard for the implementing agency CAF/VASS both within government and key sections of the National Assembly. VASS is the leading governmental research institution on social science and provides advice at the highest level on areas including socioeconomic development, poverty, health and education. It includes information gathered from the RIM studies, combined with data from the GSO and ministries, in its regular reports to senior government officials. It is suggested that these reports have had some influence over government policy since 2009.

The director of CAF also presents findings directly to both the Economic and Social Affairs Committees of the National Assembly at a time when they can be used to formulate policy. Interestingly, though VASS is a government institution, in Vietnam's context, it would appear that many National Assembly members view CAF as having a somewhat independent perspective that can be used to monitor the actions of government and provide evidence that can be used to promote effective interventions when required. There is evidence that policy has often moved in a direction that RIM findings would have recommended. It should be noted, however, that what is presented to policymakers by CAF is essentially a composite assessment based on their analysis of RIM and any other relevant data/information. The senior staff of CAF are not only skilled researchers but also have an in-depth understanding of current economic, social and political concerns. RIM certainly contributes to the policy debate but the manner and extent of that contribution would, as with data collection exercises in most other countries, be very difficult to quantify.

The RIM initiative also appears to have been endorsed and supported by many key international development partners. The studies are seen as providing rapid findings that complement existing sources, particularly in terms of wage rates, employment and broader issues relating to the labour market where data availability is seen as particularly limited. They are seen as sufficiently flexible to address a wide range of policy issues and relatively inexpensive compared to large-scale surveys. Clearly, the potential role of qualitative and participatory methodologies in providing in-depth analysis that helps to explain the findings from quantitative studies and surveys is now well established within the international community. There is recognition of the range of expertise in quantitative, qualitative and combined methods both within CAF/VASS and through collaborations with other agencies, and of the substantial experience gained over the four rounds of RIM studies undertaken between 2009 
and 2011. This is seen as having resulted in a valuable network of established relationships with local officials, enterprises, organisations and communities in the study sites.

While most agencies support RIM activities, there do seem to be diverse opinions as to what RIM should be and what precise role it should play in the future. For example, while the close relationship to government is seen as a considerable advantage in terms of policy influence, there was seen to be a possibility that this could inhibit or at least delay the distribution of findings and unduly influence the priorities for analysis. There are suggestions that the focus is predominantly economic, with only limited attempts to track impacts to household and intra-household levels.

There is also some concern that current RIM activities appear to have moved away somewhat from the original conception of a lightweight, flexible assessment of the impact of shocks and/or policy interventions. Some have suggested that this may partly relate to demands placed on the activity by international partners who have seen the possibility of gaining needed information at relatively low cost by adding components to planned studies. Long experience with household surveys would indicate the risks attached to this process and the possibility that excessive demands on RIM, possibly aligned with attractive additional funding incentives, might risk lowering the quality of data collection and/or analysis.

It would appear from a review of the methodology adopted in the 2011 rounds that there has been a tendency to shift towards instruments that resemble questionnaires, though with open-ended questions. For example, the following is one small section in a four-page instrument used in key informant interviews for which that target time is 30 minutes:

- How does village/ward leader know who jobless poor labourers are?

- Do you know any person who is jobless and who receives unemployment subsidy?

- Is there any difficulty in reception of unemployment subsidy?

- Do you see any working days created by province/district/commune to provide income for jobless poor labourers or redundant in poor or sub-poor families in the last six months?
- Do you know about vocational training for farmers last year and this year?

- How is the selection for participation into this vocational training?

- Is expertise or skills training effective?

The tendency to ask a large number of specific questions in a relatively short period of time would seem to increase the potential for misunderstandings by the respondents or misinterpretations by the interviewer. Perhaps, more significantly, it would seem to severely constrain the possibility for the emergence of novel, unexpected insights that is often seen as a primary advantage of qualitative 'interviews' as opposed to quantitative 'enumerations'. The overall impression is that the instruments are designed to test existing hypotheses rather than to explore hypotheses arising from the fieldwork, often seen as one of the features which distinguish qualitative and quantitative methodologies.

Somewhat similar issues arise in relation to the group activities that are undertaken as part of the RIM exercises. These are described as 'FGDs' but adopt a very different approach to that commonly used under this heading, which is typically taken to involve discussion around a specific theme by a group of five to eight individuals under the guidance of a facilitator, whose primary role is to listen and steer the conversation. Group activities under the RIM studies include ranking and time-lining but often seem mainly concerned to extract responses to a considerable number of very specific questions and sometimes to obtain detailed quantitative estimates, for example as the proportion of agricultural households in a given community with specific production characteristics. The review of instruments does raise more general issues as to the balance within the RIM core team in terms of expertise/experience in different disciplines, for example economics rather than sociology/anthropology, and the extent to which the demand for responses to specific predetermined questions may be excluding more innovative methods associated with those disciplines.

\section{Inclusivity}

The ten sentinel sites selected for the first round of RIM in 2009 were defined on the basis that they represent community typologies considered of specific interest and/or relevance to understand 
how the global financial crisis was affecting households and individuals in Vietnam. In some cases, this involved the selection of communities with a high concentration of people believed to be especially vulnerable to the crisis, such as migrants, industrial workers or people informally working in the construction sector. In others, those considered potentially more resilient due to their reduced exposure to the global market.

In later rounds the number of sites was increased, though the majority of those included in the first round were retained. One aim was to address diverse aspects of vulnerability; for example, the number of ethnic minority sites was increased from just one in 2009 to four in 2011. Assessment of inclusivity necessarily relies heavily on this initial selection of sites. Given that subsequent selection of enterprises, workers, unemployed workers and households was determined by the field researchers, it is not possible to assess the extent to which the voices of, for example, particularly vulnerable individuals within each of these groups would have been represented. On the one hand, the field researchers were both well qualified and experienced. On the other, they were working, especially in the later rounds to a very tight time schedule, given the range of topics to be addressed and the number of questions that were to be asked. In each site, the views of local leaders were sought and again it is not clear to what extent they would have emphasised or downplayed the situation of the more deprived sections of their communities.

\section{Relevance to users}

Discussion with the Ministry of Labour, Invalids and Social Affairs (MOLISA), which has primary responsibility for labour and social protection policy, suggested that they support the continuation of the RIM studies. MOLISA saw them as providing timely and complementary information that had particular relevance to their social protection concerns, which moved centre stage with the onset of the economic crisis. RIM could provide rapid feedback that feeds directly into policy debates, and it was generally seen as having been very influential in earlier discussions. Although MOLISA was not involved in the 2009 round, which was focused on productive activities and employment, they fully engaged with the 2010 and 2011 rounds, which began to focus on the impacts on potentially vulnerable households.
As with a number of other stakeholders, MOLISA expressed the view that RIM: (i) had become too wide-ranging and complex, and (ii) should be extended to provide more information on their specific areas of interest. MOLISA advocated a much greater focus on the impact of economic and policy change on the household, addressing areas such as income, expenditure, nutrition and social welfare. They suggested that this could be accomplished by reducing the present emphasis on enterprise and employment issues as well as by simplifying the study instruments, which had become increasingly complex and difficult to implement in the field. The original concept of a lightweight, qualitative exercise that could be rapidly implemented and analysed had to some extent been lost with increasing demands for more data.

Claims for the policy influence of RIM were supported by the chair of the Economic SubCommittee of the National Assembly. He indicated that the collaboration between the National Assembly and CAF had been extremely productive in terms of formulating policy recommendations, partly because of the paucity of reliable, current information from other sources. The Economic Committee had made considerable use of RIM findings in its policy debates, both internally and with the executive. A recent example involved a decision to end interest rate subsidies when it became evident that they were benefiting only a limited section of the population.

The ability of CAF to present these findings immediately prior to National Assembly sessions was a considerable advantage. Interestingly, the 'independence' of VASS as a policy advisor unit was also seen as a key factor, even though it is predominantly funded by government. It was suggested that this reflected the academic qualifications of its senior staff, which were highly regarded. It was argued that there was evidence to suggest that the RIM process was not influenced by undue political pressure. For example, the findings of the second round contradicted government assumptions as to the continuing very severe effects of the global crisis, and those of the third round highlighted the limited benefits of the social protection measures introduced under Resolution 11.

There were, however, limitations to the usefulness of RIM data to the National Assembly. 
Three of the main shortcomings were that: (i) it did not allow assessment of regional variations;

(ii) it was difficult to assess trends given the limited quantitative data that were collected; and (iii) there was limited data on minority populations. As with MOLISA, it was suggested that an increased emphasis on vulnerability would be in line with government concerns, given the potential effects of the necessary economic restructuring.

A representative from the Committee for Ethnic and Minority Affairs (CEMA) suggested that while RIM was undertaken in minority areas, the data on minority populations was obviously limited by the relatively small number of individuals surveyed. For example, there were 20 distinct minority groups in just one province, and policies targeting these groups had to be aware of the differences between them. The 2011 RIM has a separate section on ethnic minorities which should improve the quality and range of data. It was suggested that RIM could be useful in addressing the effects of climate change as this would have serious implications for many ethnic groups who lived in mountainous areas with a high risk of flooding.

The representative of the Institute of Policy and Strategy for Agriculture and Rural Development (IPSARD) explained that his institute was also very supportive of RIM. They had undertaken their own rapid impact exercise in 2009 to assess the impact of the economic crisis on farmers. Their researchers had worked with farmers' unions to collect data on a set of key indicators. This study collected data across eight economic regions in a very short period. However, there were considerable doubts as to its accuracy. IPSARD is currently piloting a rapid monitoring exercise which would allow it to track agricultural production. However, the exercise had been considerably more expensive than expected, and there were concerns about the potential cost of scaling up.

Oxfam had been involved in the initial discussions which led to the first round of RIM and was invited to collaborate because of its long-term involvement in poverty monitoring in Vietnam, as well as its experience in participatory and rapid assessment work. Oxfam remained supportive despite concerns that the demands on RIM had meant that it had moved away somewhat from the original concept of a very rapid, low-cost exercise. On the other hand, RIM was now more inclusive and involved more stakeholders. Oxfam regarded CAF as an excellent partner that was willing to engage in meaningful discussions on the detailed design of the studies; the main concern related to the limited release of information. Findings served as inputs and were rapidly made available to the Prime Minister's Office and the National Assembly, but there was limited access to a wider audience and then often after a substantial delay.

Among the donor community, RIM was generally well regarded. Irish Aid had contributed financial support to the most recent round. They indicated that their overall experience was positive and that RIM played an important role, given the limited monitoring data available from other sources. Their main concern was that, possibly under the influence of some donors, RIM was becoming overburdened. This was a concern shared by UNDP. Their representative argued that RIM should be restricted to tracking changes of short-term effects from any shock. The current suggestion, for example that it should be used to collect wage data, simply because this was not available from other sources, was entirely inappropriate. It should retain its focus on qualitative methods, which were well suited to understand the impact on households and their coping strategies. Again the point was made that VASS had strong direct links to the National Assembly and government. This was its major advantage in terms of influencing policy. The next step should be to institutionalise RIM. By restoring it to its original format as a lightweight rapid qualitative exercise, it should be possible for it to be funded by government. The only dissenting voice came from a key informant at the World Bank who suggested that RIM had been very useful immediately following the economic crisis but that did not imply that it should be established as a routine monitoring activity.

\section{Costs and sustainability}

No data on costs were made available during the visit, so assessment has to be made on the basis of the human resources and other inputs to the study. The formal RIM team was relatively limited, consisting of three senior staff members, 11 researchers and three support staff. The indications are that if the RIM exercises were to 
revert to their original format - rapid qualitative studies in a limited number of sites - the cost would be reasonably limited and might be acceptable to the government. However, while considerable support for RIM was provided from the National Assembly and ministries consulted, it is far from clear that it would survive without continued donor partner funding.

\section{RIM as an RTM tool}

The general perception of rapid monitoring systems is that they involve a flow of data, providing observations at frequent intervals over time, typically with the potential to trigger a response when those observations exceed given limits. Can the RIM exercises of 2009-11 be described in similar terms? It might seem more appropriate to describe them as distinct rapid impact assessments, initiated to explore the short-term economic and social consequences of specific economy-wide shocks and/or substantive changes in macroeconomic policy. Some of those involved in the first round have indicated the perception at that time that a rapid, relatively low-cost exercise by a small team of skilled researchers could at least provide a basis for action in a situation which was widely seen as a crisis, and that was probably inflicting considerable damage on a range of vulnerable people. On the other hand, the original intention was to undertake a 'series of rapid qualitative assessments' that would complement and supplement existing quantitative monitoring data. In particular, they were seen as addressing an urgent need to provide evidence as to the potential need for policy interventions given the evolving impacts of the crisis on firms, workers, unemployed workers and households.

They were also intended to explore changes over time. The study sites adopted in early 2009 have been retained through subsequent rounds, though with some additions to address supplementary questions. One objective of the round in August/September 2010 was to compare the information collected from enterprises and employees with that collected in the previous two rounds and to assess the effectiveness of coping strategies and existing safety nets that had been adopted by vulnerable groups in response to the original economic crisis. As indicated above, one aim of the round undertaken in 2011 was to review the impacts of recently introduced policy initiatives and explore consequent changes over time in employment, livelihoods and (intra) household welfare. There would also appear to be an implicit assumption, given the aim of complementing and supplementing existing quantitative monitoring systems, that there would be a continuing need for RIM exercises unless and until those systems were adapted to provide the information that RIM could deliver.

Given the above, the series of RIM exercises may be perhaps best viewed as monitoring the processes associated with the gradually unfolding effects of the 2008 economic crisis and the policy interventions intended to address those effects. They allow analysis of the changing situation of the selected enterprises, workers and households and of the coping strategies that they were adopting in response to those changes. It is important to highlight that RIM was primarily focused on productive activities, linked together by themes of employment, unemployment and internal migration, and did not attempt to address or give priority to the poorest households. As a result, the value of such an analysis will clearly depend on the extent to which the mechanisms experienced by the sampled entities can be seen as reasonably representative of those experienced by selected vulnerable sections of the population.

\section{Next steps for RTM in Vietnam}

Given the status of CAF/VASS and the generally favourable opinion of the RIM exercises that is held by most stakeholders, there would seem to be a considerable opportunity for them to become mainstreamed into the overall policymaking and review process. It seems of particular interest that presentations using data from the RIM studies are made to both the economic and social affairs committees, providing a mechanism for establishing the need to address links between economic and social policy.

It is not clear that simply repeating or further extending the range of activities conducted in 2011 in the established sites is necessarily the most useful option. As indicated above, the increasing demands being made on the studies seem to risk a reduction in quality or at best to constrain opportunities for deriving unexpected and potentially policy-relevant insights. The original purposive selection of sites was in some cases determined by factors that may reduce the extent to which findings can be generalised. It is 
not obvious that continued monitoring at some sites should be continued without careful consideration of alternatives.

One approach might be to build on the existing expertise and experience of the RIM core team to develop what might be described as a 'rapid impact assessment capacity'. CAF/VASS could identify both a core group of researchers to lead future exercises and a wider network of researchers and analysts covering a range of backgrounds to ensure that an effective team could be quickly assembled when needed to address a wide variety of issues. To ensure continuity, the National Assembly, taking into account the views of line agencies and development partners, could commission at least one strictly focused study per year. To address some existing concerns it could be required that each study should include components focusing on vulnerable groups at household and intrahousehold levels. These studies would draw on available information sources where possible but would also gather additional information when needed and feasible within resource constraints, drawing on an evolving methods toolkit.

Based on requests from the National Assembly, a working group of representatives from the Economic and Social Committees, government and all relevant development partners would agree RIM capacity building strategy each year, determine the objectives for one study each year, ensuring that these are matched to a realistic assessment of existing capacity and resource implications. Additional support would be possible in the event of external shocks that might have a serious economic and/or social impact. The working group would also set out a medium- to long-term strategy for phasing out development partner financial support to RIM.

To support the above proposal it would be helpful to establish a review panel which would identify areas (rapid appraisal, sociology, anthropology?) in which the composition and capacity of the overall pool of researchers might usefully be strengthened over time, and develop a strategy for the creation and development of a wideranging toolkit of methods that can be drawn upon in future RIM exercises. It would also be appropriate for this group to explore the potential of recent developments in information technology to both improve the quality and timeliness of data collection and reduce workloads on senior researchers. Such a panel could also consider the most appropriate means by which information on the design, implementation and findings of the RIM fieldwork might be widely disseminated, with a view to improving the quality of future RIM exercises.

Related, it would be important to evaluate the relative merits of a range of possible (probability and non-probability) sampling strategies.

Although it seems reasonable that site selection should be purposive, it would be useful to state the rationale behind selection and where possible demonstrate, using existing economic and social statistics, the extent that it can be viewed as representative of other areas. At site level, it would be important to avoid 'convenience sampling' as far as possible. This could involve the use of traditional probability sampling of enterprises, employees or locations within sites, where sampling frames (lists) exist or can be easily created, or the deliberate use of relevant chance sampling techniques - transect walks, quota sampling, etc. At the moment, the argument that respondents are not intended to be nationally representative seems to be used to imply that there is no need to seek local 'representativeness' (enterprises within sites, employees within enterprises, unemployed workers seeking employment). Deeper exploration of sampling strategies could therefore add to the confidence of external analysts in terms of interpreting findings, and could be carried out by a review panel, calling on academic experts as required.

Attempts to expand RIM data collection activities to address multiple information 'gaps' risks impacting on the validity, reliability and/or timeliness of that data. To address this issue there would seem to be advantages in establishing a government working group, including all interested parties, to determine if there are serious gaps in the existing information base for policy (e.g. data on wage rates) and formulate a strategy to generate required data over the short and medium term. The assumption should be that, where feasible, such data collection should be undertaken by GSO or central/line ministries.

There would appear to be some measure of agreement as to the need to refocus the RIM 
initiative. It was originally conceived as a rapid, relatively low resource cost, qualitative exercise to generate reliable evidence on the impacts of 'shocks'. The key consideration in any future RIM exercise should be how best to allocate scarce resources provided for this form of information gathering, in line with the intended

\section{Notes}

1 Including UNDP, UNICEF, the World Bank, DFID, Oxfam GB and ActionAid. The Ford Foundation provided support for the 2010 exercise and Irish Aid for the 2011 exercise.

2 This discussion picked up pace in Vietnam after the January 2009 regional conference

\section{References}

Anh, Nguyen Ngoc and Nguyen Thi Thu, Phuong (2010) The Social Impacts of the Global Economic Crisis on Enterprises and Workers in Vietnamese Industrial Parks, Oxfam Discussion Paper, July, www.scribd.com/doc/52828659/The-SocialImpacts-of-the-Global-Economic-Crisis-onEnterprises-and-Workers-in-VietnameseIndustrial-Parks-A-rapid-assessmentreportGiang (accessed 18 January 2013)

Giang, Nguyen Tam (2009) The Social Impacts of the Global Economic Crisis on Two Craft Villages in Vietnam, Oxfam Discussion Paper, July: 21, http://policy-practice.oxfam.org.uk/ publications/download? Id $=364375 \& \mathrm{dl}=$ http://oxfamilibrary.openrepository.com/oxfam/ bitstream/10546/1 12428/1/social-impactseconomic-crisis-craft-villages-vietnam-010209en.pdf (accessed 18 January 2013)

Phuong, Dinh Thi Thu (2010) The Social Impacts of the Global Economic Crisis on Day Labourers in use of that information by policymakers and other stakeholders. Given the relative success of RIM over the past three years, this seems a good time to reflect as to how it might best be carried forward in terms of institutional arrangements, human resources and methodologies.

organised by UNICEF on the Impact of the Global Economic Crisis on Children. A proposal to establish real-time monitoring systems was presented at this event.

\section{Mobile Labour Markets in $\mathrm{Ha}$ Noi, Oxfam}

Discussion Paper, July, http://policy-practice. oxfam.org.uk/publications/download? Id $=3643$ 49\&dl=http://oxfamilibrary.openrepository. com/oxfam/bitstream/10546/112406/1/socialimpacts-economic-crisis-labourers-mobilelabour-markets-hanoi-300710-en.pdf (accessed 18 January 2013)

Turk, Carrie and Mason, Andrew (2010) 'Impacts of the Economic Crisis in East Asia: Findings from Qualitative Monitoring in Five Countries', in Armin Bauer and Myo Thant (eds), Poverty and Sustainable Development in Asia: Impacts and Responses to the Global Economic Crisis, Manila: Asian Development Bank

UNICEF (2010) Impact of the Global Economic Crisis on Children: UNICEF Update on Real-Time Monitoring Efforts in East Asia and the Pacific Islands, Bangkok: UNICEF East Asia Pacific Regional Office 